\title{
Discussion on the Literary Thought of the Great Adept "Biography of Milarepa"
}

\author{
Lajie Zhaxi \\ School of Tibetan Language and Culture \\ Northwest Minzu University \\ Lanzhou, China 730030
}

\begin{abstract}
This paper focuses on the version of Ruibai Jingjian, discusses the unique humanistic ideological color of this biography, and elaborates the reasons why his thoughts are influenced by the Buddha's story.
\end{abstract}

Keywords-Milarepa; biography; thought characteristic

\section{INTRODUCTION}

The author of The Biography of Venerable Milarepa is Rui Bai Jingjian (1452-1507), who was born in the Duodacang area of the Tibetan, and is now in Jiangyan County. His surname is the same to that of Venerable Milarepa's the mother, namely Niang. The ancestors can be traced back to Chire Bajianzanbu, whose father is Sangji Huadan, and mother is Sangjizhen.

The writer has traveled throughout Ali to the various areas of the Tibet for this. He collected and organized all kinds of biographies, masterpieces and folklore left by the disciples of the sages, and completed orderly, rich biography of Venerable on this basis. There are more than 30 versions of different literary works in the biography of Milarepa. Among the more than 30 books, the one with most prominent literary and representativeness is the biography written by Rui Bai Jingjian, so his version was selected as the research object of this paper.

\section{THE GENERAL MEANING}

The beginning of the biography is the pass on personal teachings to pupils. Men and women, etc., gathered in front of the Venerable, and when the Venerable turns the wheel of the law for them, one day, Reqiongba is cultivating in the Zen House. Over the night, he seemed to go to the emptylined Xianyuan, and then listened to the law in front of the Aksobhya Buddha. After he woke up from the dream, he came to the Guru because he was inspired and urged by the Longevity Five Immortals. Therefore, Reqiongba knelt for long and said: "In the past, the buddhas and all the ancestors of the world have personally proclaimed their life stories for the prosperity of the world." Therefore, the Venerable Dabao, on the one hand has joy for his disciples; on the other hand, he helped all the sentient beings go on the road to mature liberation. Today, please tell your life and story of the life to public. "The Venerable said: "My Milarepa had done evil at first and later cultivated goodness. Now that both the good and the evil have been detached from the roots, he will never build any more in the future." In detail, there are both moving and ridiculous things, and there are some reasons. However, it doesn't make much sense to say that. Let me go to sleep quietly!" After that, in the pleading of Reqiongba, he promised to declare his deeds. The full text of the biography can be divided into two parts: the first part can be divided into three chapters, and the second part can be divided into nine chapters. Except for the second chapter and the ninth chapter of the second part, the rest are stories that Reqiongba ask the Venerable to declare their deeds. In this way, the excluded second chapter is the follow-up of the previous chapter, and the ninth chapter is the chapter of the body integrating to law. The above-mentioned dialogue between Venerable and apprentices shows that the biographer has sufficient documentation and has a deep understanding of the writing object.

\section{MAIN BODY}

Each literary work contains multiple themes, even if it has only one central idea. The content of work that the writer made by refining and summarizing, screening and imaging the various life phenomena is called the theme. Multiple themes and multiple images constitute the central idea of the work, and the collection of multiple themes has multiple ideological characteristics, so there are several obvious literary ideas in the biography. Because the study of biography as an example of literary works and "the study of history are two different things. Behind the fictional plots and thoughts of literary works, the background of social life and people's ideological beliefs are brewed. Literature uses vivid and meticulous methods to describe people's wishes, exchanges and thought activities. Therefore, literature is a historical material that cannot be ignored in the search for social truth and social thought." [1]Therefore, this biography shows the outline of real life, showing the author's attitude towards something. This paper describes the above characteristics respectively from the following content. 


\section{Strong ANTI-FEUdAl HuMANISTIC IDEOLOGICAL COLOR THAT REVEALS THE PSEUdO-BUDDHIST}

\section{A. Sympathizing with the Tragic Fate of Ordinary People}

The promotion of religious teachings is a common feature of all Tibetan biographies. Moreover, it borrows various metaphors to illustrate the meaninglessness of the secular. The practice of the four Buddha begins with the real social life, so the biography takes pity on and emphasize with the tragic fate of the helpless people by describing the ordinary people. For example: "Our mother and son, three people, not only did not get the property, but have to do farm work for the uncle in hot summer; in the winter, we twist yarn for the aunt; we eat the meals like dog food, but do the heavy work like a donkey; we wear tattered clothes, so I had to use a straw rope to make a belt. I worked endlessly all day, so my hands and feet were cracked. Because the food and clothing are too bad, we became withered and skinny. All those who have sympathy will cry for us after seeing or hearing this situation. Others secretly talked about the uncle and the aunt, but they ignored it. [2]From the above, it can be seen that this book describes in great detail the terrible suffering of the lower class represented by the mother and Mira. "The worldly saying goes that relying on outsiders to take care of the family, the master turns into a watchdog. This sentence happened to be fulfilled on our orphans and widows. [3] Any tragedies are likely to happen in a society where money is the supremacy. The author once again thinks and sympathizes with the survival difficulties of ordinary people.

In the eleventh century, there was a series of tragedies in the family of Gongtangjiawang mixed with happiness and joy in Mangyu, because the owner of the family died. After the death, the wolf-like people took advantage of this opportunity to hurt the mother and sons who were helpless. Although it is because of the ungrateful, insidious and sinister people that leads to the fate of the mother and the children. If it is not the will of his father, Milahi, how can the mother and Niangcagajian be so great? Her name was remembered by people because of her bravery, toughness and extraordinary wisdom.

Considering from this perspective, the testament of the father, Mila, has destroyed the happiness of the entire family. This reflected the tragic situation of women in snowy Tibetan under the patriarchal ideology. In a society where women will live in a difficult way if they leave their husbands, she raises two young children, and the burden of life didn't overwhelm her. Instead, she fought with the uncle and aunt, and punishes the enemy with her extraordinary intelligence. From this part, we also praised the courage of the lower-level laborers to never give up and resolutely fight against the ruling class. At the same time, it also praised the indomitable spirit of women.

\section{B. Uncovering the Crimes of Hegemonist}

The image of negative character: the uncle and aunt in the biography are also shaped true to life: insidious, sly, scheming, and doing bad things. After the death of the father, Mila, they swallowed the property and used the mother and sons as their own slaves. Eight years later, Milabar arrived at the age of fifteen. The mother thought that it is the high time to do something, so she sold the dowry field to exchange a lot of meat, smashed the white stalks into zanba and brew black stalks to liquor. Then she asked the relatives headed by my uncle and aunt, especially the people who was present at the death of the father Mira. Then she let the uncle read the father's testament, and then explained to the public that the son and Zeser have reached the age to have a family, so they should return the deposited financial according to the will. Uncle and aunt are harmonious at ordinary times, but they are consistent in swallowing property. They didn't give the property relying on their power. And this is described in the biography in this way:

"Where is your property? At the beginning, when Mirach was alive, those houses, gold and silver jewels, cattle and sheep livestock were all lent to him. After his death, the property certainly belongs to the original owner. Do you own a grain of gold, green barley, a pound of butter, a piece of silk, or a sheep? Today, how can you say such words! Who wrote your so-called testament? Get out of my house! [4]Then he slapped the mother in the face. The lonely mother and son were bullied by the bully at random. On the one hand, the author satirizes the hegemonic person who violates the cause and effect; on the other hand, he sympathizes with the vulnerable group and hates the high-powered hegemonic unreasonable person. In addition, when Milarepa was about to be murder by his uncle because of his revenge, the mother thought of a perfect policy to protect his son, and compiled a fake letter to his uncle in the tone of Milarepa to threaten his uncle's tricks. These reflect the wisdom of the peasants and herdsmen: "These show the people's love and desire, and reflect the spirit of resistance and struggle of the underprivileged and disadvantaged groups. This work has a strong affinity to the people. [5]Because the author's delicate description in this aspect can reveal the hate point of the opposite person, this work has also become the first literary work in Tibetan areas that supports disadvantaged groups and fights bullies. From the standpoint of the people's spokesperson, the author embodies the humanistic thinking of the whole work.

\section{Uncovering False Face of Pseudo-Buddhist}

On the one hand, Tibetan biographies encourage diligence to worship Buddha by depicting religious figures, and on the other hand, they expose the false believers who use the so-called known knowledge to defraud the masses of money; severely criticize the corrupt life of Buddhists. The following talks about how Milarepa's sister Bai Da describe the brother of the Sakya Lama Baji.

Bai Da saved the obtained wool and woven a sash around him. She did not find Milarepa at first in Zhagadasuo. She asked people and looked around. Later, she heard that a yogi like a ramie walked from the North Bank to Laduluo, and she followed it. On the way, she saw the lotsawa of the Brigade was supported by the believers on the throne and came to Milarepa and said: "in my brother's Dharma, there is no food in the mouth, no wear on the body, and shame cannot be taken care of, so it is not good. Now you can use 
this to make a skirt and see if the lotsawa can get you." [6]Through comparison of the pseudo-Buddhist who enjoys the world's wealth and the support and superstitious believers, a discarding of the world's eight laws, and believers with renuciation, it satirizes the evils of the false believers, praises the diligent cultivation of the Dharma's followers, and makes a very obvious contrast.

Moreover, the Mariba lotsawa, the master of Milarepa, is also a full exploiting class. When Milarepa was studying from him, because Milarepa did not have enough supplies to hand over, he asked him to cleanse the sin. The essence was to make Milarepa build a nine-storey tower built of flesh and blood. The work he completed today would be destroyed the next day. Because he built the house throughout the year, leaving pressure sores on the back. He also beat Milarepa for his own purposes. These cruel crimes all reflect the hatefulness of the upper class.

The above-mentioned exploitation is not only reflected in the sinful disciple Milarepa, but also in the fact that the Eba masters offered all the property to the Guru when they asked for the law, but because a broken-legged goat can't come to pay respect, he said that his teaching was a law that had been strictly sealed by the guru. Even if the goat is old and its leg is broken, it is hard to ask for law without carrying it here. Finally, Eri masters went back alone to bring the goat and presented it to the master. "The so-called secret disciple who guards the three sacred sects refers to people like you." A goat does not have much benefit for me. However, in order to achieve the depth of the law, you need to do this." [7]Then, he promised to teach him a lot of great empowerment and professors, and he really taught it. From here, we understand that the Tibetan areas at that time were not taught in India without seeking legal support, and the author also satirized the misconduct of this Buddhist monopoly. And the song of Milarepa sang: "how can the high-powered lamas dare to sit on the dilapidated seats." This also satirize that Buddhists do not care for Buddha. On the other hand, it also satirizes the sultry Buddhists who try to poison the Venerable like Joppa.

Although the period of Milarepa was not an era of chaos in Tibetan areas, there were no heads in Buddhism and culture, so Sutra and monks were prevalent everywhere. Then the monks are not subject to the original commandments, wandering everywhere, and drinking alcohol can be seen everywhere. In addition, the rituals of Bon and Buddhism are confused with each other. Also because of the prevalence of secret education, the bad custom of "convening people to come and fight when there are many people; murdering them by using sorcery if there are few people" began to appear in folk. This runs through the life of the Venerable to emphasize that future generations should not mistakenly enter the magic road, repent of the crimes committed, and follow the right path to solve the problem. In this way, only practicing Buddha's Dharma hard can obtain the final Bodhi.

\section{Praising a Saint Who Has ATtainMents in POLITICS AND RELIGION}

The biography of the great Venerable of the Tibetan history, known as the "iron-like person with the indestructible heart of copper", can be divided into two parts: in early days, he was abused by his uncle and aunt after his father's death. Later, in accordance with the wishes of the mother, he went to Wei Zhai to learn from the teacher. After a variety of tests, he learnt invocation from Yundan Gyatso in Nukelong, and learnt hailstones from the master Nianyongdongchao'erjie. After returning from school, he used curse to kill thirty-five people in the uncle and aunt's family. Then he used hailstone to destroy the crops. In the biography, Venerable Milarepa was portrayed as a heroic image that has a clear cut stand on what to love and what to hate, hold on straight to the end, and struggled in the midst of difficulties. The author also praised such a brave man who had achievements and helped the enemy. In his later years or in the second part, he resorted to the lotsawa Mazba because he repented of the deep sins of murder and arbitrage. After six years of hard work, he got the six secrets. Afterwards, he stayed far away from the world, and marched in the deep mountain secrets to practice the second round of life. Finally, he had the freedom and got the seat of King Kong. Venerable like Milarepa are rare in the snowy Tibetan areas. Master of Mariba Dai Loba predicted and admired: "In the dark and ignorant Tibetan land, there is Milarepa who shines on the earth like the sun." [8]When the masters put their heads on top and sang, the peaks and vegetation of India also bowed to Tibet for three times. This also means praise for the saints. The biography of the Venerable said that there is no heroic person besides me in the world. When Basiba was invited by the Mongolian, he said "in the palace, the king asked me what heroic people have come out of Tibet. I responded the heroic person like Venerable Milarepa has been born. He destroyed the enemy in his early years and practiced the Buddha in his late years."[9] Ba Siba also agrees with the Venerable. "When there was a Panchen Lama in the Han Dynasty, the emperor asked him that is there any brave man in Tibet. The Panchen Lama replied that there was a fearless brave man like Milarepa." [10]When the author Ruibai Jingjian began to write the biography, the name of Milarepa has been spread to Tibet. The view point that can't prove that the author intended to write for the Venerable is as follows: Like Cao Xueqin's "Dream of Red Mansions", there is no overall presupposition of the works before the author's writing. Because the creation of literature and art is carried out along the concept and core.

By quoting and combining examples, we can understand: "If the author Ruibai Jingjian did not write the biography of Milarepa, Milarepa would not have the famous reputation like the present." [11]This is an unfounded nonsense."

\section{THE BIOGRAPHICAL THOUGHT IS INFLUENCED BY THE STORY OF BUDDHA's LIFE}

Like other Tibetan biographies, the ideology of this biography has also been influenced by the story of the Indian Buddha, which is unquestionable. After the translation of the Tripitaka was introduced to Tibet, scholars from all over the 
world imitated the creative methods of Indian literature to do their own creation practice. Many biographical works created by imitating the story of Buddha's life have naturally become a tool for propagating Buddhist thoughts. Buddhist dogmata are inseparable from the content and the theme. It is beyond doubt that the Buddha has altruistic hearts and combines many previous life stories to teach disciple to let people understand the dogmata. In "The Great White Lotus classics", it is said: "Ananda, we spread the law for this, and it is not bad. To prevent it from disappearing, when it is shown to you by imitation, there are wise men that can use it to explain the reason."[12] From this quote, we can understand the usefulness, purpose, and roots of the story of Bunsen. British scholar Bodil also said: "Buddha's dogmata are mostly spread through the Buddha's story and examples."[13] This biography also explains the four truths through the reincarnation of the world: bitterness and sorrows illustrate the pain of reincarnation, and to eliminate the root causes of all these pains, it is necessary to undergo painstaking efforts to get rid of the bitter fruit, and to get rid of the troubles and get the big bodhi way after getting Nirodha-sacca. The biography emphasizes the impermanence of the cycle everywhere, and truth of cultivating Bodhisattva by renuciation.

Biography is influenced by the story of Buddha's life, mainly because of the origin of literature. This is a phenomenon that exists universally regardless of the nation and the country. In addition to Tibetan biography, foreign biography also emphasizes the ethics and morality of the human being by depicting the great deeds of the religious people, thus obtaining the blessing of God as the purpose of work. However, under the influence of the Western Renaissance, the darkness and ignorance of the last century were denied. Literature is written for the purpose of expressing real life. The characters in the works have also changed from the previous religion followers to ordinary people, and it even takes the ordinary life of farmers and merchants as the starting point. Especially after the birth of Freudian psychoanalysis, literature began to explore human nature. In modern time with advanced science and technology civilization, biographies are more popular, and the number of works is far more than the previous generation. With the improvement of people's ideological consciousness, the biographical works in the Tibetan literary world are fewer than the previous generations. The several works that have appeared have discarded the traditional creative features, which is an unhealthy trend of literary development. For example, "The Asahi khanbu biography" mentioned: "One ordinary day, the sky is blue without cloud." At this time, there is a vague sound of Sanskrit in the vast air, and people can see mysterious flash of aperture and stars in their eyes.[14] In addition, the autobiography of the great scholar Caidangerong "Self-Biography - The Dew of Truth" records: "The following is how I get the first virtue in the seven virtue".[15] The first biography did not pay much attention to the external flowery words but focused on describing historical events through mythological stories; the second was a biography written in poetry. This kind of creation that ignores the artistic figures of art shows that we have not yet understood the essence and development trend of biographies. Those who hold such thoughts believe that the language of biographical works far exceeds vernacular, so it should use ancient Chinese and gorgeous rhetoric. For example, when creating or discussing the biographies of secular people, these people will use the definition of the traditional religion to negate, and also use the definition of biography to deny the modern secular as a content of the biographies. If Tibetan literature takes the way to selfenclosement, it will not have the fresh vitality of development, and will cease to advance. In the context of a rapid development, cultural conflicts, and constant innovation, the author believes that what we need to do is to conform to the trend of the times.

\section{CONCLUSION}

As we all know, humanist literature originated in Europe in the 14th and 16th centuries and was also the subject of European literature in the Renaissance. Its main feature is anti-feudal and anti-church in the content of thoughts, especially focusing on exposing the evil deeds of exploiters and priests, singing and sympathizing with the good ideals and painful destinies of the lower classes of society. The creative method is mainly realistic writing technique to express the lively and realistic spirit of birth. The biography of "The Biography of Milarepa" is in the 15th century, and its ideological content and writing techniques can be compared with the European literary style of the same century. Only outstanding writers with noble personality and ethics can write outstanding literary works. Like all the classics of the Renaissance, this biography opens a literary barrier of epoch-making significance.

In this paper, only the humanistic part of this biography and the influence of the Buddha's story are discussed. In addition, the ideological characteristics of the religious view, view of life and view of society need to be further studied and explored.

\section{REFERENCES}

[1] NanJia Cairang. Study on lotsawa Marba [Z] Beijing: Minzu University of China, 2010.3p55.

[2] Ruibai Jingjian. Biography of Milarepa [M] Lhasa: The Tibet people's Publishing House, 2007.4.3 p20.

[3] Ruibai Jingjian. Biography of Milarepa [M] Lhasa: The Tibet people's Publishing House, 2007.4.3 p21.

[4] Ruibai Jingjian. Biography of Milarepa [M] Lhasa: The Tibet people's Publishing House, 2007.4.3 p23.

[5] Zabu. Tibetan Literature History [M] Qinghai: Qinghai Ethnic Publishing House 2002.3. p558.

[6] Ruibai Jingjian. Biography of Milarepa [M] Lhasa: The Tibet people's Publishing House, 2007.4.3 p163.

[7] Ruibai Jingjian. Biography of Milarepa [M] Lhasa: The Tibet people's Publishing House, 2007.4.3 p85.

[8] Ruibai Jingjian. Biography of Milarepa [M] Lhasa: The Tibet people's Publishing House, 2007.4.3 p102.

[9] Ewanggenggasuonan. The Sakya pedigree [M] Beijing: The Ethnic Publishing House p151.

[10] Gen Xia. Discussion on the 21st Century Tibetan Yoga Milarepa [Z] Lanzhou: Northwestern University for Nationalities p97. 
[11] Dongzhijia Collection [M] Beijing: The Ethnic Publishing House 2014.7 P49.

[12] Qiagadanzheng. How does the Buddha's biography of Buddhism affect Tibetan literature? [J] Lhasa: Tibetan Studies, 1992.1 p55.

[13] Zhaxi Dawa. Introduction to Tibetan Culture [M] Beijing: The Ethnic Publishing House, 2013.8.1p71.

[14] Luo Zhou. Biography of Cuoruo Cilang [M] Beijing: China Tibetology Press, 2006.5.1 p7.

[15] Cai Dan Xia Rong Collection The first episode [M] Beijing: The Ethnic Publishing House, 20017.4.1p42. 